\title{
Estimates of Meridional Atmosphere and Ocean Heat Transports
}

\author{
Kevin E. Trenberth and Julie M. Caron \\ National Center for Atmospheric Research,* Boulder, Colorado
}

(Manuscript received 8 November 2000, in final form 21 February 2001)

\begin{abstract}
New estimates of the poleward energy transport based on atmospheric reanalyses from the National Centers for Environmental Prediction-National Center for Atmospheric Research (NCEP-NCAR) and the European Centre for Medium-Range Weather Forecasts are presented. The analysis focuses on the period from February 1985 to April 1989 when there are reliable top-of-the-atmosphere radiation data from the Earth Radiation Budget Experiment. Annual mean poleward transports of atmospheric energy peak at $5.0 \pm 0.14 \mathrm{PW}$ at $43^{\circ} \mathrm{N}$ and with similar values near $40^{\circ} \mathrm{S}$, which is much larger than previous estimates. The standard deviation of annual and zonal mean variability from 1979 to 1998 is mostly less than 0.15 PW (1\%-3\%). Results are evaluated by computing the implied ocean heat transports, utilizing physical constraints, and comparing them with direct oceanographic estimates and those from successful stable coupled climate models that have been run without artificial flux adjustments for several centuries. Reasonable agreement among ocean transports is obtained with the disparate methods when the results from NCEP-NCAR reanalyses based upon residually derived (not modelgenerated) methods are used, and this suggests that improvements have occurred and convergence is to the true values. Atmospheric transports adjusted for spurious subterranean transports over land areas are inferred and show that poleward ocean heat transports are dominant only between $0^{\circ}$ and $17^{\circ} \mathrm{N}$. At $35^{\circ}$ latitude, at which the peak total poleward transport in each hemisphere occurs, the atmospheric transport accounts for $78 \%$ of the total in the Northern Hemisphere and $92 \%$ in the Southern Hemisphere. In general, a much greater portion of the required poleward transport is contributed by the atmosphere than the ocean, as compared with previous estimates.
\end{abstract}

\section{Introduction}

Radiative processes continually act to cool the high latitudes and warm the low latitudes of the earth, and it is only the poleward energy transport by the atmosphere and the oceans that serves to offset this. Early studies that tried to apportion how much each component contributed first estimated the required poleward heat transport from satellite measurements, then computed the atmospheric transports from observations, and finally computed the ocean transports as residuals. Moreover, this was done using zonal means (Vonder Haar and Oort 1973; Oort and Vonder Haar 1976; Trenberth 1979; Masuda 1988; Carissimo et al. 1985; Savijärvi 1988; Michaud and Derome 1991). This procedure not only assumes that the atmospheric transports are correct, it also assumes they are correct over both land and ocean, yet subsequent analyses (e.g., Trenberth and

\footnotetext{
* The National Center for Atmospheric Research is sponsored by the National Science Foundation.
}

Corresponding author address: Kevin E. Trenberth, National Center for Atmospheric Research, P.O. Box 3000, Boulder, CO $80307-$ 3000 .

E-mail: trenbert@ucar.edu
Solomon 1994) have found that there are implied subterranean transports in land areas, whereas physical constraints ensure that any such transports must be tiny as they can arise only from surface and groundwater flows plus conduction. As estimates of direct global ocean heat transports emerged (Bryden 1993), it became apparent that the atmospheric transports were likely to have been underestimated.

The studies of Vonder Haar and Oort (1973) and Oort and Vonder Haar (1976) for the Northern Hemisphere (NH) and Trenberth (1979) for the Southern Hemisphere (SH), as well as those from Carissimo et al. (1985) and Savijärvi (1988) made use of radiosonde data, but the uncertainties in the atmospheric heat transports are substantial because of lack of observations over the oceans. The uncertainties are apparent at $70^{\circ} \mathrm{S}$ in the Carissimo et al. and Savijärvi results, for instance, where there is no ocean but their residuals imply a large poleward heat transport by the ocean. Moreover, use of global analyses (Masuda 1988) indicated larger estimates of poleward atmospheric transport apparently because radiosondes fail to pick up the substantial heat transports over the oceans. However, there has been a steady trend of increases in the magnitude of the poleward energy transports in both hemispheres as atmospheric analyses have improved, and this has continued with the recent re- 
analyses. Thus the poleward ocean transports inferred using residual methods have decreased over time.

In this paper, we present new results of meridional ocean and atmosphere heat transports that are also based upon energy balance computations of the atmosphere, adjusted to fit physical constraints, using the reanalyses. The approach used is to estimate the atmospheric energy transports directly from analyses of measurements within the atmosphere. The analyses are produced using four-dimensional data assimilation, and the results have become more reliable as reanalyses of atmospheric observations to remove spurious influences of the changes in the analysis system have been carried out and satellite data have been fully utilized. We make use of the reanalyses from the National Centers for Environmental Prediction-National Center for Atmospheric Research (NCEP-NCAR) (Kalnay et al. 1996; referred to as NCEP) and the European Centre for Medium-Range Weather Forecasts (ECMWF; Gibson et al. 1997). For ECMWF the reanalyses are available for 1979 to 1993. The NCEP reanalyses are extended using the Climate Data Assimilation System (CDAS), and we use the interval 1979-98 to document the variability.

Given the top-of-the-atmosphere (TOA) radiation and the atmospheric energy divergence, the net surface heat flux can be estimated locally, and this was done for the reanalyses in Trenberth et al. (2001a). We refer to these as the "derived" surface fluxes. The TOA radiation budget from satellite measurements provides reliable estimates of the total required meridional transports of heat, and we make use of data from the Earth Radiation Budget Experiment (ERBE), which has allowed the radiation errors to be quantified much better. The ERBE data have been adjusted for biases, discontinuities when the National Oceanic and Atmospheric Administration NOAA-9 satellite was lost, and missing data that are pervasive near the delimiter of the solar radiation [Trenberth (1997); see http://www.cgd.ucar.edu/cas/catalog/ satellite/erbe/].

Hence the analysis focuses on a subperiod from February 1985 to April 1989 when ERBE data are available. The approach is to compute monthly means of all quantities and to combine the average monthly means over the ERBE period to produce an annualized mean. We make several adjustments to the fluxes so that physical constraints are satisfied to provide the best estimates of values in the real world. The constraints are the estimates of long-term changes in heat storage, the transports at the northern and southern limits of our integration, and the requirement that the TOA radiation balance the divergence of atmospheric energy over land.

To evaluate the results for the ocean, we compare the meridional transports of heat with alternative estimates from successful stable coupled climate models that have been run without artificial flux adjustments for several centuries of simulation time (Boville and Gent 1998; Gordon et al. 2000) and from multiple analyses of direct ocean measurements to determine the extent to which independent means of obtaining these quantities have converged. The results show further increases in the poleward atmospheric transports of energy when compared with previous estimates, but results are now at a point at which there is almost no scope for further changes, because the inferred ocean transports would be reduced to values outside the error bars of the direct measurements. Hence there is a convergence of the ocean transport values to be mostly within error bars, which are typically in the range of $\pm 0.3 \mathrm{PW}$ ( 1 petawatt is $10^{15} \mathrm{~W}$ ). (Results of the zonal means of the quantities from this study are available online at http://www. cgd.ucar.edu/cas/catalog/ohts/.)

Section 2 outlines the datasets used and the processing and evaluation that have already been carried out and presents results for the atmospheric transports. The implied ocean heat transports are also presented along with the adjustments made to allow for heat storage changes and to satisfy the physical constraints. Section 3 presents the ocean transports from direct ocean measurements and the coupled models and comparisons among the three approaches. It also compares the best estimates of the atmosphere and ocean energy transports with each other. Section 4 presents concluding remarks.

\section{Transports derived from atmospheric energy budgets}

\section{a. The data and processing}

The NCEP reanalyses and CDAS are based on assimilation with a numerical weather prediction (NWP) model with T62 spectral resolution and 28 sigma levels in the vertical, with five of those levels in the atmospheric boundary layer. There was a problem with the NCEP reanalyses that affected the quality of the reanalyses over the SH (see Kistler et al. 2001). The problem arose from the assimilation of the Australian Surface Pressure Bogus Data for the SH known as "PAOBS", see http://wesley.wwb.noaa.gov/paobs/ paobs.html) in which the observations were erroneously shifted by $180^{\circ}$ in longitude, affecting $1979-92$ (14 yr). PAOBS are produced for the data-poor southern oceans and are the product of human analysts who estimate sea level pressure based on satellite data, conventional data, and time continuity. Tests run on the impact of the problem indicate (i) the $\mathrm{SH}$ mid- and high latitudes $\left(40^{\circ}-\right.$ $60^{\circ} \mathrm{S}$ ) are most affected, (ii) the $\mathrm{SH}$ winter months are affected more than the SH summer months, and (iii) the differences decrease rapidly as the timescale increases from synoptic to monthly. This problem is likely to affect results over the southern oceans.

The ECMWF reanalyses (ERA-15) are at T106 resolution with 31 levels in the vertical and a hybrid coordinate that makes a transition to a pressure coordinate above about $100 \mathrm{mb}$. However, there are continuity problems with the ECMWF reanalyses arising from the positive reinforcement of biases in satellite radiances 


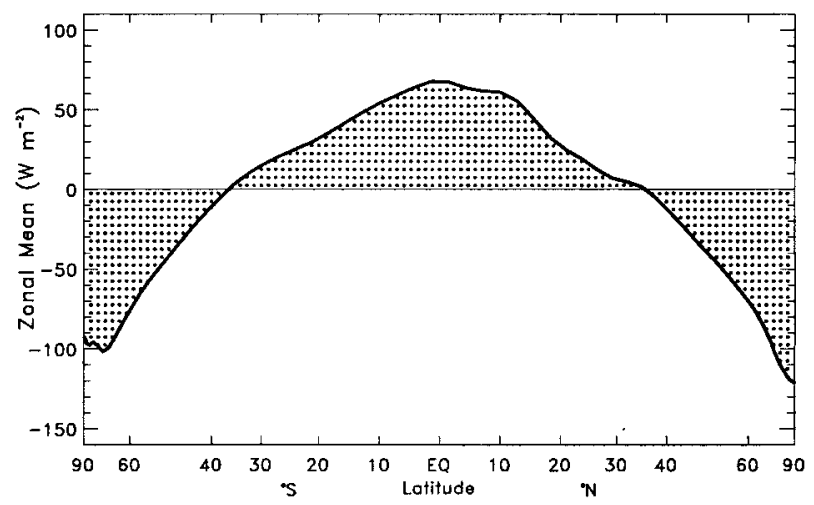

FIG. 1. TOA annualized ERBE zonal mean net radiation $\left(\mathrm{W} \mathrm{m}^{-2}\right)$ for Feb 1985-Apr 1989.

with those of the assimilating-model first guess (Trenberth et al. 2001b). Two spurious discontinuities are present in tropical temperatures, with jumps to warmer values throughout the Tropics below $500 \mathrm{mb}$ in late 1986 and early 1989, and further spurious interannual variability is also present. These features are also reflected in the specific humidity fields. The temperature discrepancies, which were identified initially using microwave sounder unit data, have a complex vertical structure with height (warming below $500 \mathrm{mb}$ but cooling in the layer above), and these problems affect moist static energy profiles and therefore poleward heat transports. The time series of tropical temperatures from the NCEP reanalyses are more consistent than those from ECMWF, and so only the NCEP results are used to examine the time series of variability.

The divergence of the monthly mean vertically integrated atmospheric energy transports from the two centers were compared for 1979-93 in Trenberth et al. (2001a). Full maps of the spatial structure of the atmospheric energy divergence, the TOA fluxes, the derived surface fluxes, and the correlations and rms differences of the monthly means were also given. For the ERBE period, net surface fluxes from the NCEP and ECMWF products were compared with each other and those from short-term $(6-12 \mathrm{~h})$ integrations of the assimilating NWP models and from the Comprehensive Ocean-Atmosphere Data Set (COADS) (da Silva et al. 1994).

Recent global air-sea flux climatological means based on ship data (COADS) and bulk formulas (da Silva et al. 1994; Josey et al. 1999) exhibit an overall global imbalance; on average the ocean gains heat at a rate of about $30 \mathrm{~W} \mathrm{~m}^{-2}$. This was adjusted by da Silva et al. (1994) by globally scaling their long-term flux estimates, but the surface fluxes are not in balance for the ERBE subperiod. Given that Josey et al. (1999) found good agreement with buoy measurements in their unadjusted flux estimates, the evidence suggests that spatially uniform corrections are not appropriate but should be done locally. Time series of monthly COADS surface

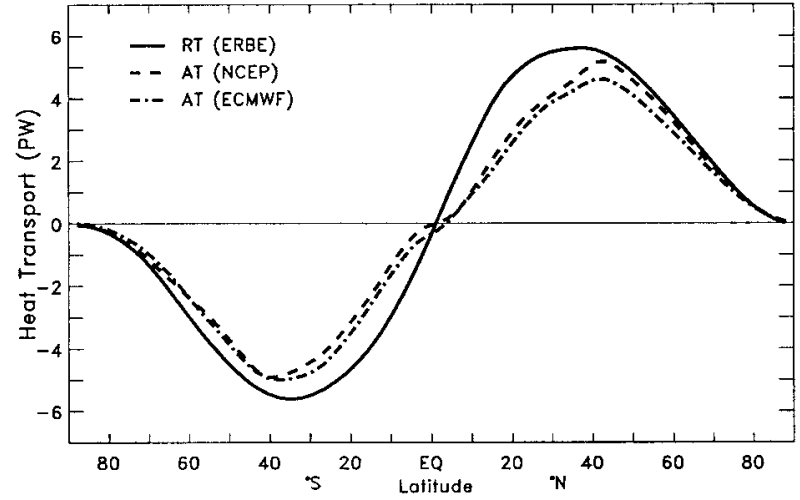

FIG. 2. The required total heat transport from the TOA radiation RT is given along with the estimates of the total atmospheric transport AT from NCEP and ECMWF reanalyses (PW).

fluxes are shown by Trenberth et al. (2001a) to be unreliable south of about $20^{\circ} \mathrm{N}$ where there are fewer than 25 observations per $5^{\circ}$ square per month. In addition, TOA biases in absorbed shortwave, outgoing longwave, and net radiation from both reanalysis NWP models are substantial $\left(>20 \mathrm{~W} \mathrm{~m}^{-2}\right.$ in the Tropics) and indicate that clouds are a primary source of problems in the NWP model fluxes, both at the surface and the TOA. As a consequence, although time series of monthly bulk flux anomalies from the two NWP models and COADS agree very well over the northern extratropical oceans, these products were all found to contain large systematic biases that make them unsuitable for determining net ocean heat transports.

The surface fluxes can then in turn be integrated meridionally to give the implied ocean northward heat transports (see Trenberth et al. 2001a). Of the products examined in that study (two derived, two NWP model, and COADS, but not including the coupled models dealt with here) only the derived surface fluxes give reasonable implied northward ocean heat transports, because the other three were corrupted by the large systematic biases.

\section{b. The atmospheric energy transports}

The zonal mean TOA energy budget from the ERBE data (Fig. 1) is used to compute the required poleward heat transport RT, which is presented along with the estimated atmospheric transports AT from both reanalyses for the same period (Fig. 2). Peak values in the $\mathrm{NH}$ of about 5.0 PW (see also Fig. 6) at $43^{\circ} \mathrm{N}$ greatly exceed the 3.1 PW of Oort and Vonder Haar (1976) and also those from the Global Weather Experiment ECMWF analyses of 4.0 PW (Masuda 1988). In Fig. 3, we present the mean northward atmospheric energy transports from NCEP as a function of month, because this allows a comparison with those of Oort and Vonder Haar (1976) for the NH. The latter featured peak northward transports of 5.0 PW in December at $63^{\circ} \mathrm{N}$, values 


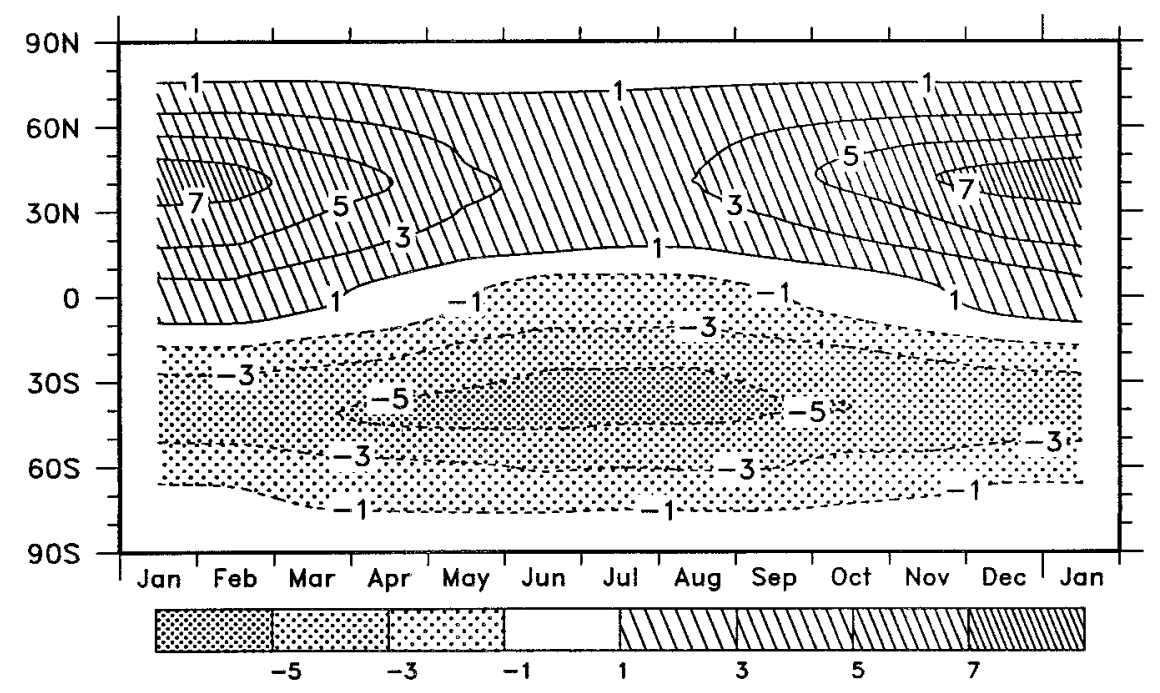

FIG. 3. The average zonal mean annual cycle of northward atmospheric energy transports for 1979-98 (PW).

exceeded 4 PW from about mid-November to the end of February, and were less than $2 \mathrm{PW}$ in summer. Figure 3 shows that the maximum poleward transports occur in winter of both hemispheres and exceed $8 \mathrm{PW}$ in the $\mathrm{NH}$, with values much greater throughout the year than those in Oort and Vonder Haar (1976). The peak poleward transport in the SH is not quite as large, but the annual cycle is much smaller.

To assess the representativeness of the ERBE period and the confidence in the estimates from an individual year, Fig. 4 presents latitude-time series for 1979-98 of the 12-month running mean departures from the mean annual cycle. At right the panel shows the standard deviation as a function of latitude, and it reveals values of almost $0.1 \mathrm{PW}$ from $30^{\circ}$ to $60^{\circ} \mathrm{N}$ but with larger variability farther south. Larger variability is not surprising in the Tropics because of El Niño-Southern Oscillation interannual variations, and these may even be underestimated in the NCEP reanalyses (Trenberth and Guillemot 1998). However, variability in Fig. 4 is greatest from about $15^{\circ}$ to $70^{\circ} \mathrm{S}$ and generally exceeds 0.15 PW. Moreover, there is a distinctive pattern to the variability, with smaller southward energy transports in 1980-85 and larger values from 1988 to 1998 . However, comparison with ERA-15 AT zonal mean time series (not shown) reveals that this pattern is not reproducible. Instead, from ERA-15 reanalyses, larger southward atmospheric transports occur from 1983 to 1988 than the mean for 1979-93 in the SH. In addition, ERA-15 annual mean standard deviations are less than $0.15 \mathrm{PW}$ at

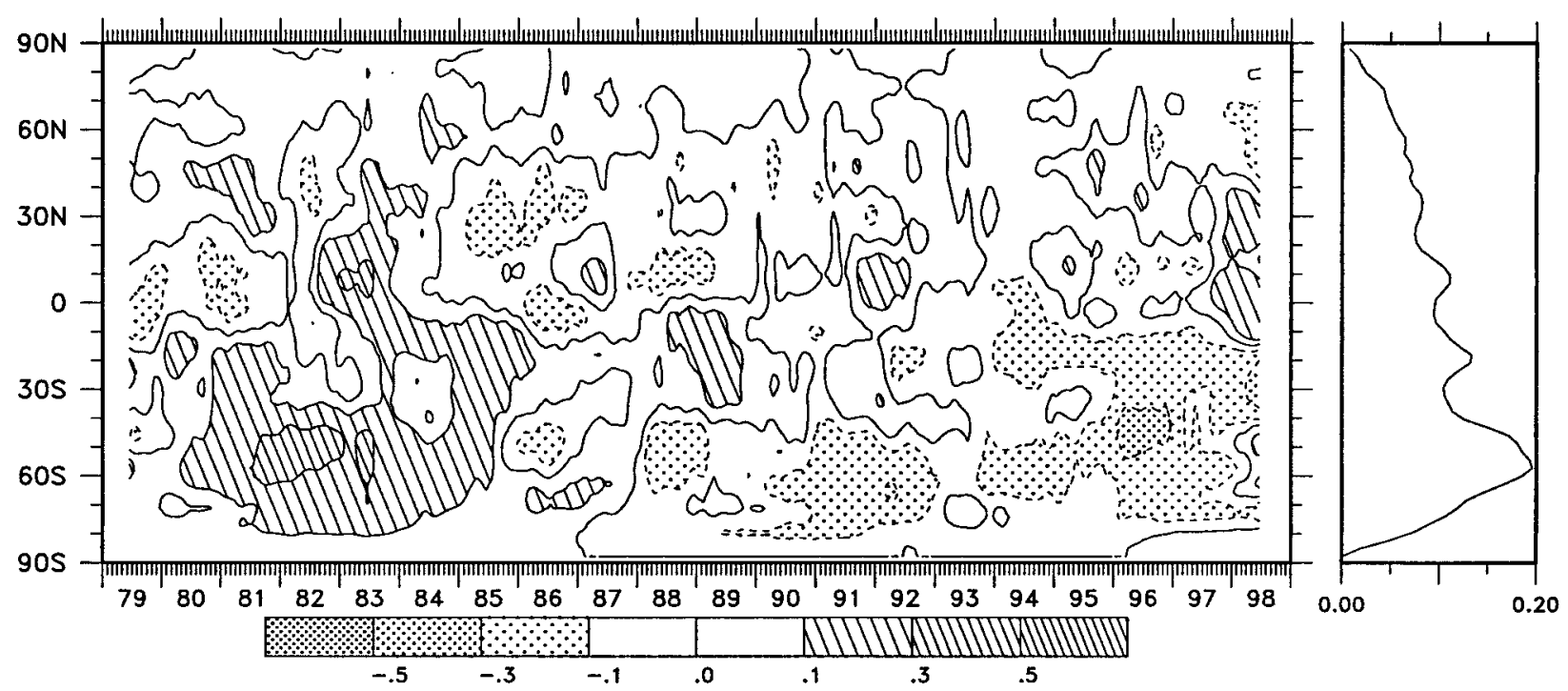

FIG. 4. Latitude-time section of the 12-month running mean of AT anomalies from the NCEP reanalyses, with the std dev given at right. 


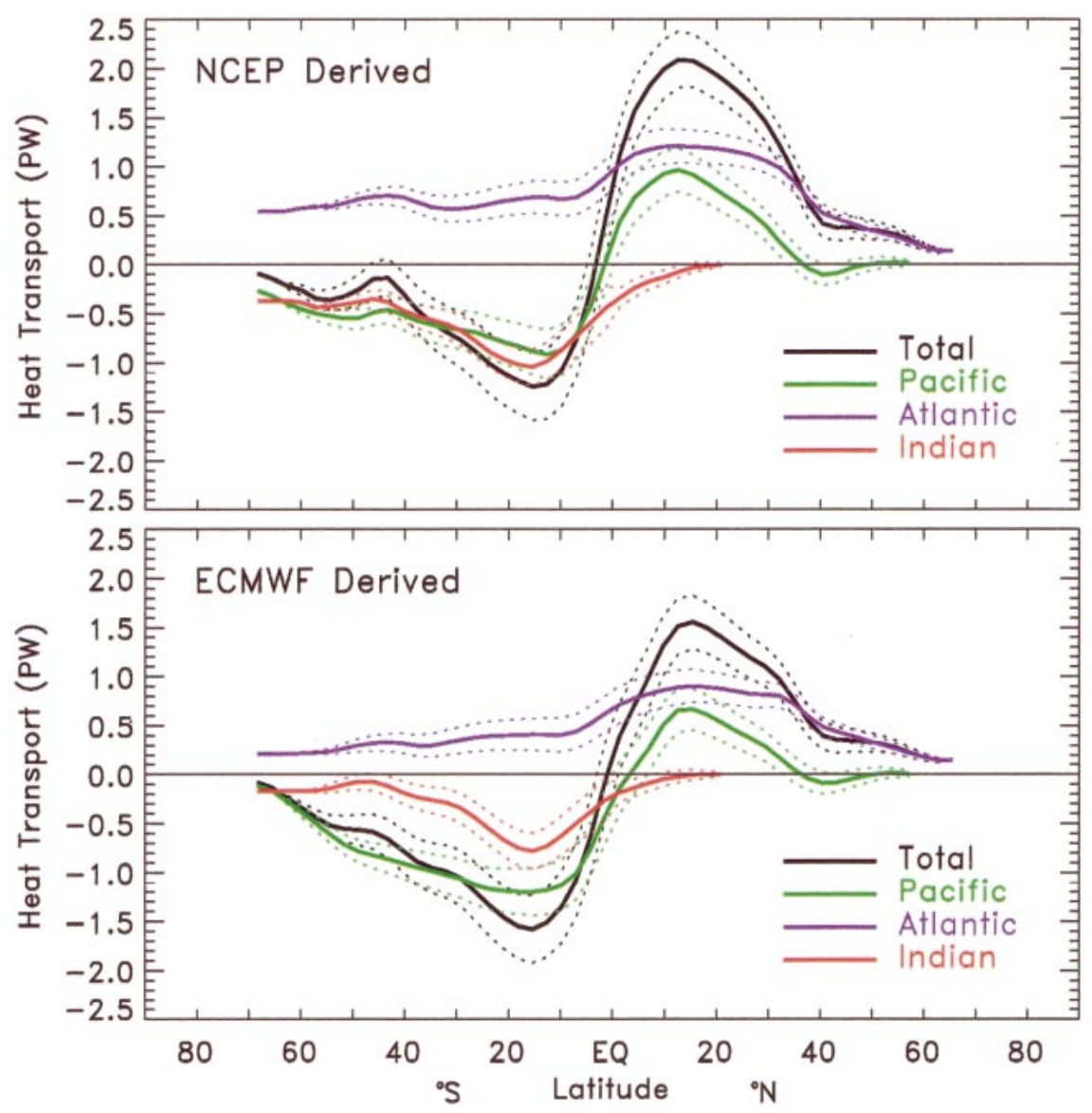

FIG. 5. Implied zonal annual mean ocean heat transports based upon the surface fluxes for Feb 1985-Apr 1989 for the total, Atlantic, Indian, and Pacific basins for NCEP and ECMWF atmospheric fields (PW). The 1 std err bars are indicated by the dashed curves.

all latitudes. The lack of reproducibility is consistent with the very small size of the interannual variability ( $1 \%-3 \%$ of the actual transports), and the main message is that temporal sampling is not a major factor.

For the ERBE period, the bias in the northward atmospheric energy transport as compared with the mean for the entire 1979-98 period is slightly negative by about $0.05 \mathrm{PW}$ from $10^{\circ}$ to $50^{\circ} \mathrm{N}$ and is positive by about $0.05 \mathrm{PW}$ from $10^{\circ}$ to $35^{\circ} \mathrm{S}$. This is consistent with the error bar estimates provided by the panel on the right of Fig. 4, with values divided by 2 (square root of the number of ERBE years), in terms of sampling.

\section{c. The derived ocean heat transports}

In Fig. 2, the difference (RT - AT) gives an implied ocean heat transport, and for NCEP, in particular, the implication is that there is almost no ocean contribution north of $45^{\circ} \mathrm{N}$. However, such an ocean estimate assumes that the long-term surface heat budget over land is in balance, because internal heat transport is negligible. Instead, such a balance does not typically exist over land, and so such an ocean estimate is contaminated by the considerable problems over land. This constraint allows the errors in atmospheric transports and surface fluxes over land to be quantified, and they are found to be largest over complex and high topography (Trenberth et al. 2001a). Therefore it is desirable to recompute the ocean transport separately based upon the implied surface fluxes over just the ocean, and in this way we can also (somewhat arbitrarily south of $35^{\circ} \mathrm{S}$ ) partition the transports into those from the individual ocean basins.

The implied zonal mean ocean transports, adjusted as discussed below, are computed from the residually derived surface fluxes (Fig. 5) starting at $65^{\circ} \mathrm{N}$ where there is a minimum of ocean available to transport heat northward. Estimates are that the transport through the Bering Strait is $0.2 \times 10^{13} \mathrm{~W}$, and that in the North Atlantic is $1.4 \times 10^{14} \mathrm{~W}$ (Aagaard and Greisman 1975). Therefore we use $0.14 \mathrm{PW}$ at $65^{\circ} \mathrm{N}$ as the starting point of our integration in the Atlantic. We set the dividing line between the Atlantic and Indian Ocean at $25^{\circ} \mathrm{E}$, directly south of Africa. The Atlantic and the Pacific are separated at $70^{\circ} \mathrm{W}$, south of South America. For the Pacific and Indian Oceans, we use $130^{\circ} \mathrm{E}$ from $5^{\circ} \mathrm{S}$ to south of Australia and $100^{\circ} \mathrm{E}$ north of $5^{\circ} \mathrm{S}$. Although integration 
of the surface fluxes readily partitions the contributions by basin, the result cannot necessarily be interpreted as a heat transport unless the mass budget is closed. The Indian and Pacific Ocean partition is confounded by the Indonesian Throughflow, so that ocean mass flow in each basin is not closed, and only their sum is meaningful as a heat transport. The computations were done on a T42 grid $\left(2.8^{\circ}\right)$ as a compromise between the requirement for high resolution to resolve islands and the ocean basin configurations and the need to smooth the analysis fields to suppress the small-scale noise. The same domains and procedures were used for each product.

The second adjustment considers systematic changes in heat storage in the ocean. Largest interannual changes in upper-ocean heat content probably occur in association with El Niño (e.g., Sun and Trenberth 1998). To gain some idea of the magnitude of these effects on our results, we have computed Pacific zonal averages of vertically integrated heat content above $400 \mathrm{~m}$ using ocean analyses of the tropical Pacific from the Environmental Modeling Center at NCEP. We use a monthly mean analysis from 1980 to 1998 derived from weekly analyses using the RA6 schemes described by Behringer et al. (1998). Zonal mean anomalies for both the starting month, February 1985, and ending month, April 1989, are small when compared with other parts of the time series and are on the order of $5 \times 10^{8} \mathrm{~J} \mathrm{~m}^{-2}$. The computed heat storage changes peak at 2 times this value near $18^{\circ} \mathrm{N}$, and this converts to zonal mean changes of $8 \mathrm{~W} \mathrm{~m}^{-2}$ for the Pacific, or about $0.06 \mathrm{PW}$ over $5^{\circ}$ latitude. Moreover, such changes are local and are often part of a meridional dipole indicating movement of heat within the ocean. Because the values are fairly small and tend to cancel when integrated over about $30^{\circ}$ latitude and there is not an adequate global ocean analysis available to assess local tendencies in heat storage, we have ignored changes in ocean heat storage except for the systematic warming trends.

Because of changes in atmospheric composition, the radiation at the TOA is likely to be out of balance by a few tenths of watts per meter squared. The imbalance is not measurable, and the ERBE data were adjusted to require a global balance between the absorbed and outgoing radiation. However, the imbalance is expected to be manifested in the oceans, and there is evidence that a systematic warming of the global oceans is occurring (Levitus et al. 2000), with a magnitude of $0.3 \mathrm{~W} \mathrm{~m}^{-2}$ overall. For 1985-88 in the upper $300 \mathrm{~m}$, for which there is annual resolution, the warming appears to be $0.50 \pm 0.35 \mathrm{~W} \mathrm{~m}^{-2}$. We take the first value as more representative of the overall changes because of uncertainties from sampling the high-frequency variability. Integrated over the oceans, this would contribute to an apparent transport at $68^{\circ} \mathrm{S}$ of $-0.1 \mathrm{PW}$, which also provides the magnitude of this adjustment on the implied heat transports. To treat it as a change in heat storage, we subtract the $0.3 \mathrm{~W} \mathrm{~m}^{-2}$ from the surface fluxes uni- formly throughout the ocean, consistent with the global nature of the changes shown in Levitus et al. (2000). Although it can be argued that the treatment of the TOA radiation is inconsistent with that at the surface, the adjustment is small and in the direction required to achieve a balance in the oceans.

The third adjustment is to close the budget. Because we began the integration from the north and the global oceans are a closed system, any accumulated bias shows up as the imbalance at the southernmost latitude, taken as $68^{\circ} \mathrm{S}$ owing to seasonal ice cover. The imbalances, shown in Trenberth et al. (2001a), were adjusted as follows. The coupled ocean models (Boville and Gent 1998; Gordon et al. 2000) have northward ocean heat transports at $68^{\circ} \mathrm{S}$ that average $-0.1 \pm 0.05 \mathrm{PW}$. Hence we require that the total northward heat transport must tend to $-0.1 \mathrm{PW}$ at $68^{\circ} \mathrm{S}$. Further we assume that the main errors arise over the southern oceans south of $30^{\circ} \mathrm{S}$, because they are so sparsely observed. This is also compatible with the problems revealed in COADS, the analysis of Josey et al. (1999), and the problems in the NCEP reanalyses with the PAOBS.

Thus, small adjustments are made to the surface heat flux over one or more of the southern oceans depending upon the sign of the residual versus the residual in the oceans south of $30^{\circ} \mathrm{S}$. The northward heat transports by the Atlantic and Indian Oceans were combined because of the strong interbasin transports south of Africa and the role of Agulhas rings (Saunders and King 1995; Macdonald and Wunsch 1996). The computed total northward heat transport at $68^{\circ} \mathrm{S}$ has imbalances of -0.1 PW for NCEP-derived and -0.7 PW for ECMWF-derived products. These correspond to global surface flux imbalances of 0.3 and $2.3 \mathrm{~W} \mathrm{~m}^{-2}$, respectively. Because the imbalance is negative for both NCEP- and ECMWFderived fields and the Atlantic Ocean transport is positive (northward), the adjustments imposed on the Pacific Ocean were of about $2 \mathrm{~W} \mathrm{~m}^{-2}$ for NCEP and 16 $\mathrm{W} \mathrm{m} \mathrm{m}^{-2}$ for ECMWF from $30^{\circ}$ to $68^{\circ} \mathrm{S}$. This is the result plotted in Fig. 5. Note that the magnitude of the adjustments that we have applied to satisfy the global physical constraints is very small for NCEP.

Based upon computed root-mean-square differences and correlations between monthly fields of the ECMWF- and NCEP-derived surface fluxes, random errors of 25-30 $\mathrm{W} \mathrm{m}^{-2}$ for $\mathrm{T} 31$ resolution (scales of about $500 \mathrm{~km}$ ) over the oceans are estimated (Trenberth et al. 2001a). The spatial power spectrum of the atmospheric energy divergence is slightly red, suggesting some spatial coherence. Here, the errors are accumulated by integrating from each northern and southern limit, which will somewhat underestimate southern ocean error bars, because they are not constrained except for the total for all oceans and because of the adjustments. Rather than performing a formal error analysis, we use the empirical estimate of errors and have plotted error bars in Fig. 5 that assume random errors of $30 \mathrm{~W} \mathrm{~m}^{-2}$ over $1000-\mathrm{km}$ scales, which approximately takes the spatial coherence 
into account but is probably a slight overestimate in the NH.

\section{Comparison among estimates}

\section{a. Direct ocean observations}

The direct method for estimating ocean heat transport is where the products of ocean velocity and temperature measured over the boundaries of a closed volume are integrated to determine the ocean heat transport divergence for the volume. The advantage is that it deals with ocean circulation and the mechanisms of ocean heat transport. The disadvantages have been that estimates could only be made at a few locations for which high quality observations were available and that several assumptions, such as using geostrophic velocity estimates, are usually employed. As noted below, another substantial disadvantage is inadequate temporal sampling and resolution of the annual cycle.

Making direct estimates of heat transport from transoceanic sections in each ocean basin was a primary objective in designing the World Ocean Circulation Experiment (WOCE) field program. Several WOCE section results are now also available, and a synthesis of the WOCE results is under way. Macdonald and Wunsch (1996) and Macdonald (1998) made a synthesis of selected high-quality hydrographic sections covering all ocean basins, many taken prior to the WOCE observational period, to produce consistent meridional heat transports using a global inverse analysis. Other recent examples are those by Holfort and Siedler (2001) for the South Atlantic and Ganachaud and Wunsch (2000), both of which use inverse models to make a best fit of observational constraints based upon measurements of mass, heat, salt, oxygen, nitrate, phosphate, silica, and carbon. Sources of errors are extensively discussed, see especially Holfort and Siedler (2001). For the heat flux, the greatest uncertainties arise from the surface wind stress and temporal variability.

Koltermann et al. (1999) reexamined hydrographic data taken over the past $40 \mathrm{yr}$ in the North Atlantic and found physically consistent evidence for low-frequency decadal changes within the ocean that produced changes in meridional ocean heat transport from 0.5 PW (195759) to $1.3 \mathrm{PW}(1981-82)$ at $36^{\circ} \mathrm{N}$ and smaller changes of several tenths of a petawatt at $24^{\circ} \mathrm{N}$ and $45^{\circ} \mathrm{N}$. However, independent analysis of all available data at $36^{\circ} \mathrm{N}$ by Sato and Rossby (2000) shows that aliasing can occur because of variations with the seasons and spatial and temporal sampling. They find a mean annual northward heat transport of $1.2 \pm 0.3 \mathrm{PW}$ but with a range in the annual cycle of $0.6 \pm 0.1 \mathrm{PW}$. Once the annual cycle is accounted for, they find interannual variations within $0.1 \mathrm{PW}$. However, individual sections have a standard deviation of $0.3 \mathrm{PW}$, owing largely to eddy variability. Similar conclusions are arrived at by Roemmich et al. (2001) for the subtropical North Pacific (mean latitude $22^{\circ} \mathrm{N}$ ) in which they find a northward ocean heat transport of $0.77 \pm 0.12 \mathrm{PW}$ based upon 25 transects but with an interannual variability of $0.3 \mathrm{PW}$. It is apparent that many error bar estimates are conservative, given that they do not bridge the range of values found in different analyses of the same data.

In the Atlantic (Fig. 6, top panel), where there are the most abundant ocean observations, there is northward ocean heat transport at all latitudes, mainly associated with the thermohaline circulation in which North Atlantic Deep Water is formed in the polar and subpolar North Atlantic and subsequently flows southward throughout the Atlantic. The most reliable single value is regarded as that at $24.5^{\circ} \mathrm{N}$ across the Atlantic, at which location a recent reassessment that included the WOCE section in 1992 by Lavin et al. (1998) gave the best value of $1.27 \pm 0.26 \mathrm{PW}$, somewhat larger than the $1.07 \pm 0.26$ PW estimated by Macdonald (1998) but similar to the Ganachaud and Wunsch (2000) estimate of $1.3 \pm 0.15 \mathrm{PW}$. The error uncertainty range quoted in the first two estimates includes uncertainty in variability in the Bering Strait and other regions. The picture is rather different in the Pacific (not shown), where a northward heat flux in the North Pacific is due principally to a shallow Ekman-upper thermocline cell (Wijffels et al. 1996) and values at $24^{\circ} \mathrm{N}$ are estimated as $0.76 \pm 0.3$ (Bryden et al. 1991), $0.45 \pm 0.26$ (Macdonald 1998), and 0.53 \pm 0.24 PW (Ganachaud and Wunsch 2000).

Some other Atlantic Ocean heat transport estimates plotted in Fig. 6 with the error bars from the authors include Bacon (1997) at $\sim 55^{\circ} \mathrm{N}$ of $0.28 \pm 0.06 \mathrm{PW}$, Klein et al. (1995) at $14.5^{\circ} \mathrm{N}$ of $1.22 \pm 0.42 \mathrm{PW}$, Speer et al. (1996) at $11^{\circ} \mathrm{S}$ of $0.60 \pm 0.17 \mathrm{PW}$, and Saunders and King (1995) at about $40^{\circ} \mathrm{S}$ of $0.53 \pm 0.1 \mathrm{PW}$. At $30^{\circ} \mathrm{S}$ Holfort and Seidler (2001) estimate a mean northward transport of $0.29 \pm 0.24 \mathrm{PW}$ as compared with $0.35 \pm 0.15$ PW by Ganachaud and Wunsch (2000). The Ganachaud and Wunsch (2000) values fluctuate; at $30^{\circ} \mathrm{S}$ their value is $0.3 \mathrm{PW}$ less than that near $40^{\circ} \mathrm{S}$ and $0.45 \mathrm{PW}$ less than at $19^{\circ} \mathrm{S}$, implying a strong dipole in surface heat flux of over $100 \mathrm{~W} \mathrm{~m}^{-2}$ across $30^{\circ} \mathrm{S}$ that is not seen in maps of surface fluxes (Trenberth et al. 2001a). Similarly, the value at $7^{\circ} \mathrm{N}$ is smaller than values to both the north $\left(24^{\circ} \mathrm{N}\right)$ and south $\left(5^{\circ} \mathrm{S}\right)$ by amounts that seem unlikely. It is accordingly important to recognize the large error bars in these regions.

For the "World Ocean" (Fig. 6, bottom panel) at $24^{\circ} \mathrm{N}$, values range from $1.5 \pm 0.3 \mathrm{PW}$ (Macdonald and Wunsch 1996) to $2.0 \pm 0.3 \mathrm{PW}$ from the sum of the Lavin et al. and Bryden et al. values, with Ganachaud and Wunsch (2000) in between at $1.83 \pm 0.28 \mathrm{PW}$. For the South Pacific (Tsimplis et al. 1998; Koshlyakov and Sazhina 1995) and Indian Oceans (Robbins and Toole 1997), the determination of ocean heat transport is clouded by uncertainties in the size of the Indonesian Throughflow and the Agulhas Current transports (Beal and Bryden 1997), and the estimates of northward heat 
transport across $30^{\circ} \mathrm{S}$ in the Indian Ocean range from -0.4 to $-1.3 \mathrm{PW}$ (Robbins and Toole 1997; Macdonald 1998). At $30^{\circ} \mathrm{S}$, the total Macdonald and Wunsch (1996) estimate is $-0.9 \pm 0.3 \mathrm{PW}$ as compared with $-0.6 \pm$ $0.3 \mathrm{PW}$ for Ganachaud and Wunsch (2000).

\section{b. Coupled models}

Recent coupled ocean-atmosphere models from NCAR the Climate System Model, CSM; (Boville and Gent 1998) and the Hadley Centre (HADCM3; Gordon et al. 2000) have been run successfully for several hundred years without artificial adjustments to the modeled surface heat fluxes, often called "flux adjustment." This implies that the surface air-sea heat and water fluxes calculated by the model are reasonably consistent with the simulated ocean heat and freshwater transports. Improvements in both the atmospheric (Hack 1998) and oceanic (Doney et al. 1998; Large and Gent 1999) modules of the climate models are believed to be responsible for this. Long-term drifts in the subsurface ocean have been addressed (Boville et al. 2001). Problems are most apparent in the freshwater budgets. For instance, the intertropical convergence zone (ITCZ) may spuriously migrate from one hemisphere to the other, seriously distorting the precipitation fields (e.g., Boville and Gent 1998). Nevertheless, this achievement by two groups is in effect a reconciliation of the atmospheric and oceanic modules as to what the meridional heat transport by the atmosphere and the ocean should be, and so this provides measures of these vital quantities, which have heretofore been highly uncertain. However, the question of how well they agree with those in the real world remains and is addressed here.

Figure 6 shows the coupled model results in the center panel for the Atlantic and the bottom panel for the World Ocean. For the Atlantic, the two models agree well with each other in the SH; CSM values are as much as 0.3 PW larger in the North Atlantic. These differences are also reflected in the World Ocean. At $24^{\circ} \mathrm{N}$, values are 1.67 PW (World) and 1.14 PW (Atlantic) for HADCM3 versus $2.02 \mathrm{PW}$ and $1.31 \mathrm{PW}$ for CSM; at $30^{\circ} \mathrm{S}$, differences of $0.07 \mathrm{PW}$ are smaller $(-0.68$ for HADCM3 vs -0.61 for CSM).

\section{c. Comparisons with derived values}

Figure 6 facilitates the comparisons among these different estimates. We compare the World Ocean and Atlantic ocean values in that order. For the direct ocean estimates at $24^{\circ} \mathrm{N}$, NCEP-derived values (1.8 and 1.1 PW) fall within the observational uncertainties. In contrast, both ECMWF-derived values $(1.3,0.8 \mathrm{PW})$ are too low which, because this is also true in the comparison with the coupled model results, suggests that there are deficiencies in the ECMWF result. At $30^{\circ} \mathrm{S}$ for the World Ocean, the values of $-0.8 \mathrm{PW}$ for NCEP-derived results and $-1.1 \mathrm{PW}$ for ECMWF-derived results are within error bars of the direct estimate. The CSM ( -0.6 PW) and HADCM3 ( -0.7 PW) models suggest slightly smaller southward transports, but the differences are within the error bars. In the Atlantic at $30^{\circ} \mathrm{S}$, the ECMWF-derived values are much lower than those for NCEP, but the scatter in direct estimates does not discriminate which may be right. Given the ECMWF bias at $68^{\circ} \mathrm{S}$, however, which required the adjustment of 0.7 PW, the NCEP result is preferred there, too.

In the North Atlantic, the northward ocean heat transports by both coupled models are high relative to both the derived results and the direct observations by Bacon (1997) at $55^{\circ} \mathrm{N}$. CSM, in particular, seems to have ocean transports that are too large in the North Atlantic. A recent improvement in CSM, in which a river runoff routing scheme has been implemented (E. Brady 2000, personal communication), that appropriately transports the freshwater flow into the Arctic and North Atlantic, has substantially reduced the northward ocean heat transports in the CSM-simulated Atlantic. There is otherwise mostly good agreement between the two models and the NCEP estimates. It is perhaps noteworthy that the only exceptions to the agreement with the direct ocean estimates are those derived from the inverse modeling, which depend on use of a model.

\section{d. Relative transports}

To show more clearly the relative roles of the atmosphere and ocean transports. Fig. 7 presents the required transport RT, as in Fig. 2, along with the adjusted derived ocean transport OT from the NCEP reanalyses and the atmospheric transport AT as their difference. The latter can be compared with the raw estimates given in Fig. 2, and the differences are $-0.2 \mathrm{PW}$ near $40^{\circ} \mathrm{N}$ for AT, growing to about $-0.4 \mathrm{PW}$ from $0^{\circ}$ to $60^{\circ} \mathrm{S}$ for NCEP. For ECMWF (not shown), the changes are greater, and, in particular, AT has to increase by $0.2 \mathrm{PW}$ at $65^{\circ} \mathrm{N}$, where the ocean role is tiny, and by $0.4 \mathrm{PW}$ at $68^{\circ} \mathrm{S}$, where the ocean role vanishes and thus is well defined. At $24^{\circ} \mathrm{N}$ the ECMWF AT increases by $0.6 \mathrm{PW}$. Aside from the changes at the northern and southern boundaries, which are small for NCEP, the differences exist mainly from the implied adjustments over land plus the small ocean adjustments south of $30^{\circ} \mathrm{S}$. For the NCEP results, a spurious downward surface flux into the land in the NH (Trenberth et al. 2001a) results in lower adjusted northward AT throughout the globe. There is greater symmetry about the equator in the ECMWF atmospheric and oceanic transports (not shown), which is belied by the evidence of northward transport throughout the Atlantic Ocean.

There is now excellent agreement between NCEP and ECMWF AT north of $45^{\circ} \mathrm{N}$, where the inferred OT is small. The peak AT value is $5.0 \pm 0.14 \mathrm{PW}$ at $43^{\circ} \mathrm{N}$. However, in the $\mathrm{SH}$ south of $40^{\circ} \mathrm{S}$, the level of agreement between the two atmospheric transports evident in Fig. 2 is no longer as good. The peak southward atmospheric 


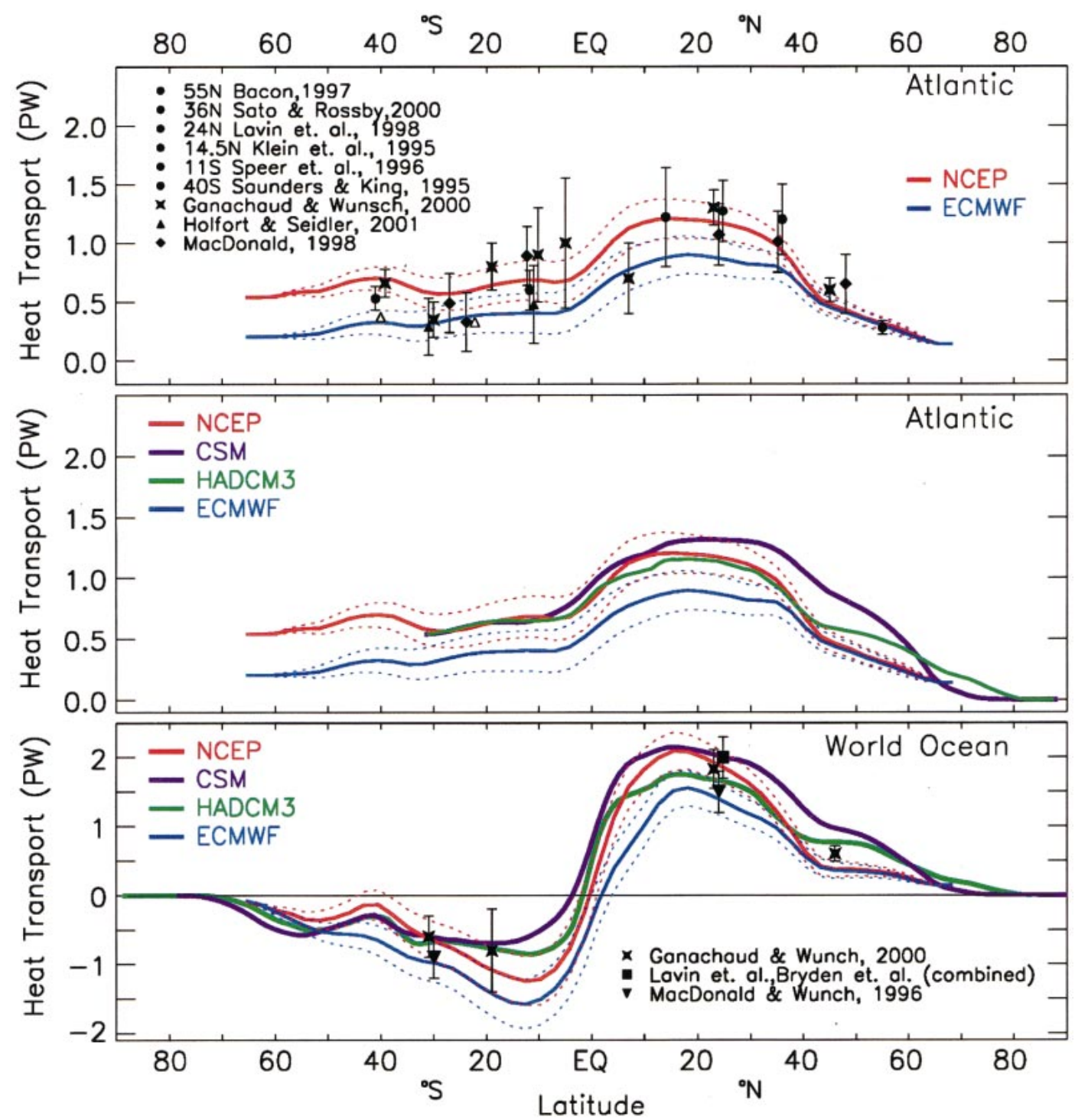

FIG. 6. The northward ocean heat transports from the NCEP-derived and ECMWF-derived products are compared (top) for the Atlantic Ocean with direct ocean estimates from sections, as identified in the key. The dashed curves show the \pm 1 std err for the derived transports. Where given in the original source, error bars are also plotted and the symbol is solid. Slight offsets in latitude are introduced where overlap would otherwise occur. Several sections are not exactly along a latitude circle, notably those for Bacon (1997) at $\sim 55^{\circ} \mathrm{N}$ and the Saunders and King (1995) section along $45^{\circ} \mathrm{S}$ (South America to $10^{\circ} \mathrm{E}$ ) to $35^{\circ} \mathrm{S}$ (Africa), plotted at $40^{\circ} \mathrm{S}$. (middle) Comparison of the derived results with transports from the HADCM3 (years 81-120) and CSM (years 250-299) coupled models for the Atlantic. (bottom) Results for the global ocean along with those from Macdonald and Wunsch $(1996)$ at $24^{\circ} \mathrm{N}$ and $30^{\circ} \mathrm{S}$, and at $24^{\circ} \mathrm{N}$ the combined Lavin et al. (1998) and Bryden et al. (1991) and for Ganachaud and Wunsch (2000).

transport in Fig. 7 is $-5.3 \pm 0.2 \mathrm{PW}$ at $40^{\circ} \mathrm{S}$, as compared with -4.9 PW in Fig. 2. Because the magnitude of this change is two standard errors, the latter may be underestimated.

At $35^{\circ}$ latitude, which is very close to where the peak total poleward transport in each hemisphere occurs, the total atmospheric transport accounts for $78 \%$ of the total in the $\mathrm{NH}$ and $92 \%$ in the $\mathrm{SH}$. In general, a much greater portion of the required poleward transport is contributed by the atmosphere than the ocean as compared with previous estimates. It is only from the equator to $17^{\circ} \mathrm{N}$ that the poleward ocean transports exceed those from the atmosphere.

\section{Concluding remarks}

There is overall very good agreement between the NCEP-derived ocean heat transport and those from the coupled models and direct ocean measurements; the ECMWF-derived values appear to be somewhat defi- 


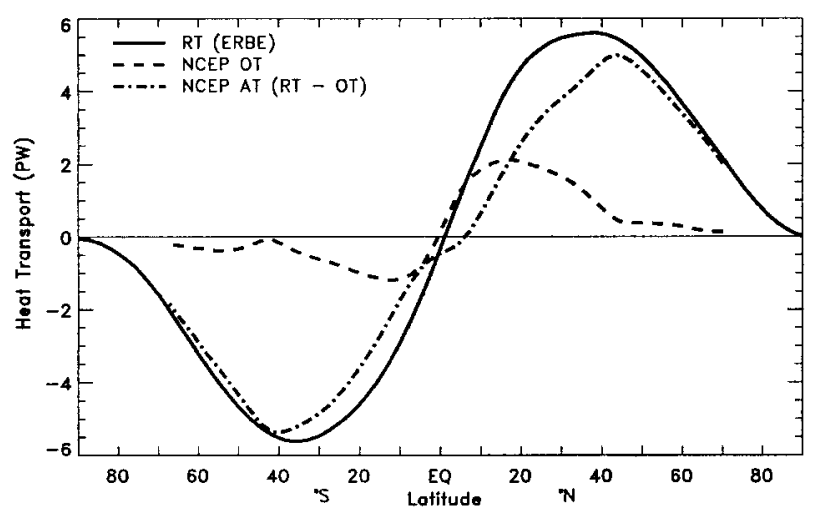

FIG. 7. The required total heat transport from the TOA radiation RT is compared with the derived estimate of the adjusted ocean heat transport OT (dashed) and implied atmospheric transport AT from NCEP reanalyses (PW).

cient. This result is especially so at $24^{\circ} \mathrm{N}$ at which latitude no adjustments have been applied to either derived OT estimate. Further, the adjustments applied south of $30^{\circ} \mathrm{S}$ are miniscule for NCEP but amount to $0.7 \mathrm{PW}$ at $68^{\circ} \mathrm{S}$ for ECMWF OT or $0.4 \mathrm{PW}$ for ECMWF AT (the difference being integrated effects from the north vs the south), suggesting also that the latter are less reliable in absolute values. In the Tropics, the problems with changes in the observing system, particularly satellite data, adversely influence the ECMWF results (Trenberth et al. 2001b), which are not within the error bounds of the other estimates at several latitudes.

Aside from the North Atlantic, for which the coupled model results are high for reasons that are beginning to be understood (section 3c), the largest discrepancy among the results is in the SH Tropics, where the NCEPderived values imply a larger southward transport than do the direct ocean estimates or the coupled climate models. This is in a region where Ekman transports play a key role and surface wind specifications are very uncertain. For instance, at $11^{\circ} \mathrm{S}$ a change in mean wind alters the direct estimate from 0.48 to $0.63 \mathrm{PW}$ in the Atlantic (Holfort and Seidler 2001), and in coupledmodel simulations tropical convergence zones are often dislocated in some seasons when a spurious ITCZ forms in the $\mathrm{SH}$, potentially corrupting values in the Tropics (Boville and Gent 1998).

We have inferred the surface fluxes and thus the zonal mean ocean heat transports assuming no changes in ocean heat storage except for those associated with global warming. The local ocean heat storage change is not neglible from year to year (Sun and Trenberth 1998), although it is a reasonable assumption for zonal means for the four years or so we used here provided that the global warming trend is factored in, as we have done. Future computations should factor in the changes in ocean heat storage to examine the ocean heat transports locally using this method. Variability in AT from sampling this particular interval is mostly less than $0.05 \mathrm{PW}$ and is not a major factor, although interannual variability is not very reproducible between ECMWF and NCEP reanalyses. TOA radiation fluxes also contain some uncertainty, and adjustments for expected imbalances at the TOA may be a refinement worth considering in future.

It is important to note that although the ocean heat transports and surface fluxes derived from the TOA radiation plus the atmospheric transports (the indirect method) have improved substantially and mostly agree with the independent estimates the same cannot be said for the atmospheric NWP model surface fluxes computed with bulk parameterizations, which contain substantial biases. The NWP models have not yet been improved to satisfy the global energy budgets in the same way that the best coupled climate models have, highlighting the facts that weather prediction is constrained by the specification of the SSTs and the models do not have to get the SST tendencies correct to produce excellent weather forecasts.

Shortcomings in the hydrological cycle in the NCEP reanalyses in the Tropics (Trenberth and Guillemot 1998) suggest that they have limitations, although, because there is huge compensation between the budgets for dry static energy and the moist component, the total energy transport is more robustly computed (Trenberth and Solomon 1994). The discrepancies between the atmospheric transports in the two reanalyses suggest that further revisions will occur, especially regionally. Nevertheless, the results for the ocean heat transports derived from the NCEP reanalyses are in good agreement with those from the other approaches, suggesting that the coupled models, the atmospheric transports, and the independently estimated ocean transports are converging to the correct values.

Acknowledgments. This research was sponsored by NOAA Office of Global Programs Grant NA56GP0247 and the joint NOAA-NASA Grant NA87GP0105. Many thanks to Dave Stepaniak for computing the atmospheric energy transports.

\section{REFERENCES}

Aagaard, K., and P. Greisman, 1975: Toward new mass and heat budgets for the Arctic Ocean. J. Geophys. Res., 80, 3821-3827.

Bacon, S., 1997: Circulation and fluxes in the North Atlantic between Greenland and Ireland. J. Phys. Oceanogr., 27, 1420-1435.

Beal, L. M., and H. L. Bryden, 1997: Observations of an Agulhas Undercurrent. Deep-Sea Res. I, 44, 1715-1724.

Behringer, D. W., M. Ji, and A. Leetmaa, 1998: An improved coupled model for ENSO prediction and implications for ocean initialization. Part I: The ocean data assimilation system. Mon. Wea. Rev., 126, 1013-1021.

Boville, B. A., and P. R. Gent, 1998: The NCAR Climate System Model, version one. J. Climate, 11, 1115-1130.

— J. T. Kiehl, P. J. Rasch, and F. O. Bryan, 2001: Improvements to the NCAR CSM-1 for transient climate simulations. J. Climate, 14, 164-179.

Bryden, H. L., 1993: Ocean heat transport across $24^{\circ} \mathrm{N}$ latitude. Interactions between Global Climate Subsystems, The Legacy of 
Hann, Geophys. Monogr., No. 75, IUGG and Amer. Geophys. Union, 65-75.

, D. H. Roemmich, and J. A. Church, 1991: Ocean heat transport across $24^{\circ} \mathrm{N}$ in the Pacific. Deep-Sea Res., 38, 297-324.

Carissimo, B. C., A. H. Oort, and T. H. Vonder Haar, 1985: Estimating the meridional energy transports in the atmosphere and ocean. J. Phys. Oceanogr., 15, 82-91.

da Silva, A. M., C. C. Young, and S. Levitus, 1994: Algorithms and Procedures. Vol. 1, Atlas of Surface Marine Data 1994, NOAA Atlas NESDIS, $83 \mathrm{pp}$

Doney, S. C., W. G. Large, and F. O. Bryan, 1998: Surface ocean fluxes and water-mass transformation rates in the coupled NCAR climate system model. J. Climate, 11, 1420-1441.

Ganachaud, A., and C. Wunsch, 2000: Improved estimates of global ocean circulation, heat transport and mixing from hydrological data. Nature, 408, 453-457.

Gibson, J. K., P. Källberg, S. Uppala, A. Hernandez, A. Nomura, and E. Serrano, 1997: ERA description. ECMWF Reanalysis Project Rep. 1, 72 pp.

Gordon, C., C. Cooper, C. A. Senior, H. Banks, J. M. Gregory, T. C. Johns, J. F. B. Mitchell, and R. A. Wood, 2000: The simulation of SST, sea ice extents and ocean heat transports in a version of the Hadley Centre coupled model without flux adjustments. Climate Dyn., 16, 147-168.

Hack, J. J., 1998: Analysis of the improvement in implied meridional ocean energy transport as simulated by the NCAR CCM3. $J$. Climate, 11, 1237-1244.

Holfort, J., and G. Siedler, 2001: The meridional oceanic transports of heat and nutrients in the South Atlantic. J. Phys. Oceanogr., 31, 5-29.

Josey, S. A., E. C. Kent, and P. K. Taylor, 1999: New insights into the ocean heat budget closure problem from analysis of the SOC air-sea flux climatology. J. Climate, 12, 2856-2880.

Kalnay, E., and Coauthors,1996: The NCEP/NCAR 40-Year Reanalysis Project. Bull. Amer. Meteor. Soc., 77, 437-471.

Kistler, R., and Coauthors, 2001: The NCEP-NCAR 50-year reanalysis: Monthly means CD-ROM and documentation. Bull. Amer. Meteor. Soc., 82, 247-267.

Klein, B., R. L. Molinari, T. J. Muller, and G. Siedler, 1995: A transatlantic section at $14.5^{\circ} \mathrm{N}$ : Meridional volume and heat fluxes. J. Mar. Res., 53, 929-957.

Koltermann, K. P., A. V. Sokov, V. P. Tereschenkov, S. A. Dobroliubov, K. Lorbacher, and A. Sy, 1999: Decadal changes in the thermohaline circulation of the North Atlantic. Deep-Sea Res. II, 46, 109-138

Koshlyakov, M. N., and T. G. Sazhina, 1996: Meridional volume and heat transport by large-scale geostrophic currents in the Pacific sector of the Antarctic (English translation). Oceanology, 35, $767-777$.

Large, W. G., and P. R. Gent, 1999: Validation of vertical mixing in an equatorial ocean model using large eddy simulations and observations. J. Phys. Oceanogr., 29, 449-464.

Lavin, A., H. L. Bryden, and G. Parrilla, 1998: Meridional transport and heat flux variations in the subtropical North Atlantic. Global Atmos. Ocean Syst., 6, 269-293.

Levitus, S., J. I. Antonov, T. P. Boyer, and C. Stephens, 2000: Warming of the World Ocean. Science, 287, 2225-2229.
Macdonald, A. M., 1998: The global ocean circulation: A hydrographic estimate and regional analysis. Progress in Oceanography, Vol. 41, Pergamon, 281-382.

- , and C. Wunsch, 1996: An estimate of global ocean circulation and heat fluxes. Nature, 382, 436-439.

Masuda, K., 1988: Meridional heat transport by the atmosphere and the ocean; Analysis of FGGE data. Tellus, 40A, 285-302.

Michaud, R., and J. Derome, 1991: On the mean meridional transport of energy in the atmosphere and oceans as derived from six years of ECMWF analyses. Tellus, 43A, 1-14.

Oort, A. H., and T. H. Vonder Haar, 1976: On the observed annual cycle in the ocean-atmosphere heat balance over the Northern Hemisphere. J. Phys. Oceanogr., 6, 781-800.

Robbins, P. E., and J. M. Toole, 1997: The dissolved silica budget as a constraint on the meridional overturning circulation of the Indian Ocean. Deep-Sea Res. I, 44, 879-906.

Roemmich, D., J. Gibson, B. Cornuelle, and R. Weller, 2001: The mean and time-varying meridional transport of heat at the tropical/subtropical boundary of the North Pacific Ocean. J. Geophys. Res. 106, 8957-8970.

Sato, O. T., and T. Rossby, 2000: Seasonal and low-frequency variability of the meridional heat flux at $36^{\circ} \mathrm{N}$ in the North Atlantic. J. Phys. Oceanogr., 30, 606-621.

Saunders, P. M., and B. A. King, 1995: Oceanic fluxes on the WOCE A11 section. J. Phys. Oceanogr., 25, 1942-1958.

Savijärvi, H. I., 1988: Global energy and moisture budgets from rawinsonde data. Mon. Wea. Rev., 116, 417-430.

Speer, K. G., J. Holfort, T. Reynard, and G. Siedler, 1996: South Atlantic heat transport at $11^{\circ} \mathrm{S}$. The South Atlantic: Present and Past Circulation, G. Wefer, W. H. Berger, G. Siedler, and D. J. Webb, Eds., Springer, 105-120.

Sun, D.-Z., and K. E. Trenberth, 1998: Coordinated heat removal from the tropical Pacific during the 1986-87 El Niño. Geophys. Res. Lett., 25, 2659-2662.

Trenberth, K. E., 1979: Mean annual poleward energy transports by the oceans in the Southern Hemisphere. Dyn. Atmos. Oceans, $\mathbf{4}$ $57-64$.

1997: Using atmospheric budgets as a constraint on surface fluxes. J. Climate, 10, 2796-2809.

, and A. Solomon, 1994: The global heat balance: Heat transports in the atmosphere and ocean. Climate Dyn., 10, 107-134.

and C. J. Guillemot, 1998: Evaluation of the atmospheric moisture and hydrological cycle in the NCEP/NCAR reanalyses. $\mathrm{Cli}$ mate Dyn., 14, 213-231.

_ J. M. Caron, and D. P. Stepaniak, 2001a: The atmospheric energy budget and implications for surface fluxes and ocean heat transports. Climate Dyn., 17, 259-276.

— D. P. Stepaniak, J. W. Hurrell, and M. Fiorino, 2001b: Quality of reanalyses in the Tropics. J. Climate, 14, 1499-1510.

Tsimplis, M. N., S. Bacon, and H. L. Bryden, 1998: The circulation of the sub-tropical South Pacific derived from hydrographic data. J. Geophys. Res., 103, 21 443-21 468.

Vonder Haar, T. H., and A. H. Oort, 1973: A new estimate of annual poleward energy transport by the oceans. J. Phys. Oceanogr., 3, $169-172$.

Wijffels, S. E., J. M. Toole, H. L. Bryden, R. A. Fine, W. J. Jenkins, and J. L. Bullister, 1996: The water masses and circulation at $10^{\circ} \mathrm{N}$ in the Pacific. Deep-Sea Res., 43, 501-544. 